\title{
Neurodevelopmental Constraints of Syntax Rule Transfer Effects as Landmarks for Sensitive Periods of Language Acquisition
}

\author{
Michael A. Skeide \\ Department of Neuropsychology, Max Planck Institute for Human Cognitive and Brain Sciences, 04103 Leipzig, Germany \\ Review of Vaughan-Evans et al.
}

\begin{abstract}
Mastering syntactic rules, which determine how words are combined into phrases, is crucial for understanding language. There is a longstanding debate in the literature concerning the formation of such rules. Some authors have argued that in adults the cognitive implementation of syntax is based on the implicit learning of abstract rules (Opitz and Friederici, 2004), whereas others have claimed that it depends instead on the explicit learning of associations between distinct lexical items that share certain phonological features (Thierry and $\mathrm{Wu}, 2007$ ). Less is known, however, about how children acquire a first- and second-language syntax (Kuhl, 2010). It is not clear what the developmental constraints of acquiring a fullfledged syntax are, nor to what extent these constraints are determined by the maturation of the brain (Clahsen and Felser, 2006).

In a recent article in The Journal of $\mathrm{Neu}$ roscience, Vaughan-Evans et al. (2014) provide evidence based on event-related potentials (ERPs) that a syntactic rule existing in only one of two languages covertly carries over from that language to
\end{abstract}

Received July 17, 2014; revised Aug. 16, 2014; accepted Aug. 20, 2014. I thank Angela D. Friederici and Emiliano Zaccarella for helpful comments on this manuscript and Elizabeth Kelly for proofreading.

Correspondence should be addressed to Michael A. Skeide, Max Planck Institute for Human Cognitive and Brain Sciences, Stephanstrasse 1a, 04103 Leipzig, Germany. E-mail: skeide@cbs.mpg.de.

DOI:10.1523/JNEUROSCI.2921-14.2014

Copyright $\odot 2014$ the authors $\quad 0270-6474 / 14 / 3413279-02 \$ 15.00 / 0$ the other. The authors resolve a conceptually important issue by suggesting that the cognitive implementation of syntax is not governed by lexical-phonological associative learning but rather by abstract rule learning.

The Welsh-English bilingual participants of the study read English sentences ending in an artificial non-word created by substituting the initial consonant of a real English word with another consonant, as sometimes happens in Welsh. In particular, the Welsh soft mutation rule determines whether and how the initial consonant of a noun changes as a function of certain phrase contexts (e.g., "cath," i.e., "cat," mutates into "gath" in the phrase "y gath," i.e., "the cat"). A context in which the mutation would occur in Welsh was present in one half of the English sentences. Additionally, half of the sentences contained forms that were in accordance with the soft mutation rule (e.g., in the sentence "Each book starts with a page listing its gontents," "contents" correctly mutates into "gontents," as would occur in Welsh), whereas the other half contained aberrant forms (e.g., in the sentence "Each book starts with a page listing its dontents," "contents" wrongly mutates into "dontents").

The authors used the phonological mismatch negativity (PMN), an ERP component modulated by phonological predictions about the initial letter of an upcoming word, to determine whether the Welsh soft mutation rule influenced perception of English sentences. They found that the PMN amplitude was significantly lower for words mutated in compliance with the Welsh rule than for aberrant forms. This amplitude reduction occurred only when the word appeared in a context that required a mutation in Welsh, as reflected in a significant mutation context $\times$ word form interaction. This result suggests that it was substantially less demanding for the participants to integrate a non-word into a sentence context in one language when the nonword was formed in compliance with a syntactic rule of the other language than when the non-word violated the rule. Crucially, this transfer effect occurred regardless of whether there was phoneme overlap between the original English noun and the corresponding Welsh noun (e.g., "Each book starts with a page listing its gontents," where "gynnwys" is the Welsh counterpart, elicited transfer effects similar to "As a doctor she saw a lot of patients," where "gleifion" is the Welsh counterpart). Therefore, the effect could not be explained by lexical-phonological associations.

It is important to note that the implications of the findings reported by Vaughan-Evans et al. (2014) for our understanding of the neurodevelopmental constraints of syntax acquisition are limited. This seems to be clear to the authors as well, as they explicitly state 
that follow-up studies are necessary to shed more light on the developmental dynamics of syntactic transfer. The limitation of the experiment is that the paradigm used by the authors only allowed them to test for a syntax transfer effect from the first language (Welsh), learned from birth on, to the second language (English), learned at a mean age of 4.9 years, but not vice versa. From a developmental perspective, however, the question that arises is: What is the crucial age at which second language syntax can transfer to the syntax of the first language? This is of particular conceptual significance since the transferability of syntactic rules learned later in life could be a good indicator of whether this syntax is fully established in a second language or not.

Converging evidence ranging from the pioneering studies of second language learning (Johnson and Newport, 1989) to more recent attempts to explore the milestones of language development (Sakai, 2005) suggests that children do not acquire syntactic rules with full accuracy if they start learning a second language after 7 years of age, when their syntactic learning capacities start to decline. These results are interesting because this beginning decline of syntactic learning capacities coincides with the age where the early left anterior negativity, an ERP component reflecting syntactic categorization processes, starts to take on an adult-like appearance in monolingual children (Hahne et al., 2004). Thus, beyond 7 years of age, when a core set of rules is already established in the syntax processing system, it might lose the flexibility to fully implement a new syntax. Nevertheless, controversies remain regarding the critical age up to which a second language syntax can be fully acquired. Some studies indicate that significant deficits in syntax processing are present only if the second language is learned at $8-10$ years of age (Johnson and Newport, 1989), whereas others report similar deficits are already present at 4-6 years of age (Weber-Fox and Neville, 1996). The success of future studies addressing the developmental dynamics of syntax implementation by test- ing syntactic rule transferability crucially depends on the ability to gather multiple samples of adult bilinguals that are tightly matched for their age of onset of second language acquisition. As a start, it would be tempting to compare bilinguals that started to learn their second language either from 4 or 7 years of age with bilinguals that started to learn their second language from 12 years of age, the age currently assumed to mark the end of the sensitive period of language acquisition (Sakai, 2005).

Vaughan-Evans et al. (2014) rightly emphasize that ERPs are a powerful technique to detect covert transfer of syntax rules between languages. However, although ERPs clearly overcome the limitations of previous behavioral work, they provide little information about the functional neural implementation of syntactic transfer. To further elucidate the developmental dynamics of this effect, the use of fMRI would be advantageous. It is known from previous work that simultaneous bilinguals, i.e., individuals that learn two languages from birth on, have similar representations of syntactic information from both languages, whereas sequential bilinguals with a mean age of second language acquisition onset of 18.9 years recruit not only the left inferior frontal cortex but also left subcortical structures, i.e., the basal ganglia and the thalamus, more strongly for the second than for the first language when processing syntactic features (Wartenburger et al., 2003). There is evidence that the additional recruitment of subcortical structures in late second language learners indicates increased processing demands for these people than for simultaneous bilinguals, because late second language learners can no longer rely solely on automatic processes (Friederici, 2006). Crucially, the emergence of subcortical activity during a syntax transfer task could mark the trajectory from a learning phase where syntax transfer can take place to a phase where such transfer is no longer possible.

In summary, the work of VaughanEvans et al. (2014) raises the question, from which age of onset of second lan- guage acquisition can syntax transfer from the second to the first language. It also raises the tightly related question of whether the emergence of subcortical activity during syntax transfer might serve as a dissociative functional marker of transfer and nontransfer periods. These questions address not only the temporal developmental constraints for the full acquisition of syntactic rules, thereby leading to the core of language learning, but also the opening and closing of sensitive periods in language acquisition, thereby leading to the core of neuroplasticity.

\section{References}

Clahsen H, Felser C (2006) How native-like is non-native language processing? Trends Cogn Sci 10:564-570. CrossRef Medline

Friederici AD (2006) What's in control of language? Nat Neurosci 9:991-992. CrossRef Medline

Hahne A, Eckstein K, Friederici AD (2004) Brain signatures of syntactic and semantic processes during children's language development. J Cogn Neurosci 16:1302-1318. CrossRef Medline

Johnson JS, Newport EL (1989) Critical period effects in second language learning: the influence of maturational state on the acquisition of English as a second language. Cogn Psychol 21:60-99. CrossRef Medline

Kuhl PK (2010) Brain mechanisms in early language acquisition. Neuron 67:713-727. CrossRef Medline

Opitz B, Friederici AD (2004) Brain correlates of language learning: the neuronal dissociation of rule-based versus similarity-based learning. J Neurosci 24:8436-8440. CrossRef Medline

Sakai KL (2005) Language acquisition and brain development. Science 310:815-819. CrossRef Medline

Thierry G, Wu YJ (2007) Brain potentials reveal unconscious translation during foreignlanguage comprehension. Proc Natl Acad Sci U S A 104:12530-12535. CrossRef Medline

Vaughan-Evans A, Kuipers JR, Thierry G, Jones MW (2014) Anomalous transfer of syntax between languages. J Neurosci 34:8333-8335. CrossRef Medline

Wartenburger I, Heekeren HR, Abutalebi J, Cappa SF, Villringer A, Perani D (2003) Early setting of grammatical processing in the bilingual brain. Neuron 37:159-170. CrossRef Medline

Weber-Fox CM, Neville HJ (1996) Maturational constraints on functional specializations for language processing: ERP and behavioral evidence in bilingual speakers. J Cogn Neurosci 8:231-256. CrossRef Medline 